\title{
Ocorrência do parasitóide Labena fiorii sp.n. (Hymenoptera, Ichneumonidae) em larvas de Hedypathes betulinus (Klug), broca da erva-mate e em Chydarteres striatus (Fabricius), broca da aroeira, (Coleoptera, Cerambycidae) ${ }^{1}$
}

\author{
Vinalto Graf ${ }^{2}$ \\ Márcia Ribeiro Marzagão ${ }^{3}$
}

\begin{abstract}
Labena fiorii sp.n. (Hymenoptera, Ichneumonidae), parasitoid of Hedypathes betulinus (Klug) and Chydarteres striatus (Fabricius) (Coleoptera, Cerambycidae). The borer beetle Hedypathes betulinus, plague of "erva-mate" (Ilex paraguariensis St. Hil., 1822), has been subject of study aiming its biological control. Larvae of this insect digs galleries in the stem and branches of this tree, difficulting its control. Labena fiorii sp.n. was found in branches of this tree, parasitizing larvae of Hedypathes betulinus in Teixeira Soares and in "aroeira" (Schinus sp.) in larvae of Chydarteres striatus (Fabricius, 1787) in Curitiba, Paraná, Brazil. Labena fiorii sp.n., from Paraná (Curitiba; Teixeira Soares) and Santa Catarina (Seara, Nova Teutônia) Brazil, is described.

KEY WORDS. Cerambycidae, Ichneumonidae, Labena fiorii sp.n., erva-mate, aroeira
\end{abstract}

No município de Teixeira Soares, Paraná, foram coletadas larvas de Hedypathes betulinus (Klug, 1825) (Coleoptera, Cerambycidae) parasitadas por Labena fiorii sp.n. (Hymenoptera, Ichneumonidae) a partir de galhos da erva-mate, derrubados pela ação do vento, onde os coleópteros efetuaram as galerias.

H. betulinus é considerada a principal praga da erva-mate (Ilex paraguariensis S. Hil., 1822 - Aquifoliaceae) e vem sendo objeto de estudo no sentido de se melhorar as condições dessa cultura. A descoberta deste novo inimigo natural vem contribuir para o seu controle biológico. Espécimens de Labena fiorii sp.n. também foram obtidos em laboratório em aroeira (Schinus sp. - Anacardiaceae), coletada em Curitiba, no bosque do "Parque da Cidade" e atacada por Chydarteres striatus (Fabricius, 1787) - Cerambycidae.

A nova espécie de Labena Cresson, 1864 foi comparada com as outras da coleção e da literatura (Cresson 1874; CuSHMAn 1922; GAULD \& Holloway 1986; KRIECHBAUMER 1889; ROHWER 1920; SZÉPligeti 1914; TOWNES \& TOWNES 1966; WAHL 1996) e descrita a seguir.

Todas as medidas são fornecidas em milímetros.

1) Contribuição número 1022 do Departamento de Zoologia, Universidade Federal do Paraná

2) Departamento de Zoologia, Universidade Federal do Paraná. Caixa Postal 19020 81531-990 Curitiba, Paraná, Brasil. Bolsista do CNPq.

3) Departamento de Silvicultura, Universidade Federal do Paraná. Curitiba, Paraná, Brasil. Bolsista da CAPES. 


\section{Labena fiorii sp.n.}

Figs 1-7

Fêmea. Coloração: marrom-escura, com áreas pretas, ferrugíneas e amarelas. Cabeça preta; clípeo, área malar, base da mandíbula, ferrugíneas; órbitas interna e externa com faixa estreita amarelada, interrompida na gena inferior e no vértice; a faixa na órbita externa continua no vértice atrás dos ocelos, mas interrompida entre os ocelos laterais e os olhos; fronte e vértice enegrecidos com áreas abaixo do ocelo médio e nos lados da fronte ferrugíneo-enegrecidas. Maxilas e lábio pretos com a glossa amarelada. Antenas pretas, o escapo, no lado ventral, amarelado e flagelômeros XVIII a XXIII amarelo-alaranjados.

Mesoscuto preto, com faixa lateral e duas manchas posteriores amareladas; tégulas, lados do pronoto, mesopleura, metapleura e propódeo marrom-ferrugíneos; lados do pronoto (pequenas áreas ovais anteriores), propleura, margem anterior e parte inferior da mesopleura, área abaixo da tégula, espéculo, mesosterno, margem posterior e lados do escutelo e do pós-escutelo, axilas, margens anterior da metapleura e do propódeo, enegrecidas a pretas; escutelo, pós-escutelo, mesoepimero e áreas súpero-média e dentíparas do propódeo, amarelas. Asas tingidas de marrom, as anteriores em toda extensão da parte anterior marrom-escura, incluindo as células basal, discosubmarginal, marginal, metade da terceira submarginal, sub-basal, a base da primeira subdiscal e metade da anal. Asas posteriores mais claras que as anteriores; células basal e sub-basal mais escurecidas. Pernas marrons, mas enegrecidas: nas anteriores, a coxa e face posterior do trocanter, trocantelo, fêmur e tíbia; nas pernas médias, a base e a face posterior da coxa e a parte média, dilatada e externa da tíbia; nas pernas posteriores, a margem distal da coxa, a junção do trocantelo e fêmur e a margem externa da tíbia. Metassoma marrom-enegrecido, primeiro tergo marrom-amarelado, com faixa estreita transversal subapical amarelada, valvas do ovipositor marrons com o ápice enegrecido e ovipositor ferrugineoenegrecido.

Face um pouco proeminente no meio, pontuação densa, os intervalos dos pontos pouco elevados e unidos formando delicadas rugas verticais no meio e oblíquas nos lados, pontuação muito fina na faixa orbital interna. Clípeo finamente pontuado na parte distal, na área sub-basal com faixa transversal lisa e brilhante, com curtas rugas na parte inferior. Área malar com a metade da largura basal da mandíbula, fosca a finamente pontuada com algumas estrias junto ao clípeo. Mandíbula com finas rugas basais na face externa. Gena com pontuação esparsa e fina, mais densa e com rugas finas na sua região inferior; pontuação muito densa e fina no vértice e nos lados dos ocelos laterais; rugas verticais entre os alvéolos antenais. Occipício liso, com pontuação numa faixa interna à carena occipital, que se alarga inferiormente. Carena occipital completa, fraca acima, ventralmente em lâmina, unida à carena hipostomal num ângulo obtuso $\left(130^{\circ}\right)$, distante da base da mandíbula. Faixa orbital externa lisa e brilhante, no vértice mais estreita. Vértice proeminente atrás dos ocelos e separado destes por sulco transversal, a distância pós-ocelar igual a ocelocular $(0,36: 0,36)$, os espaços internos dos ocelos laterais elevados. Pronoto convexo látero-posteriormente, com depressão junto à margem 

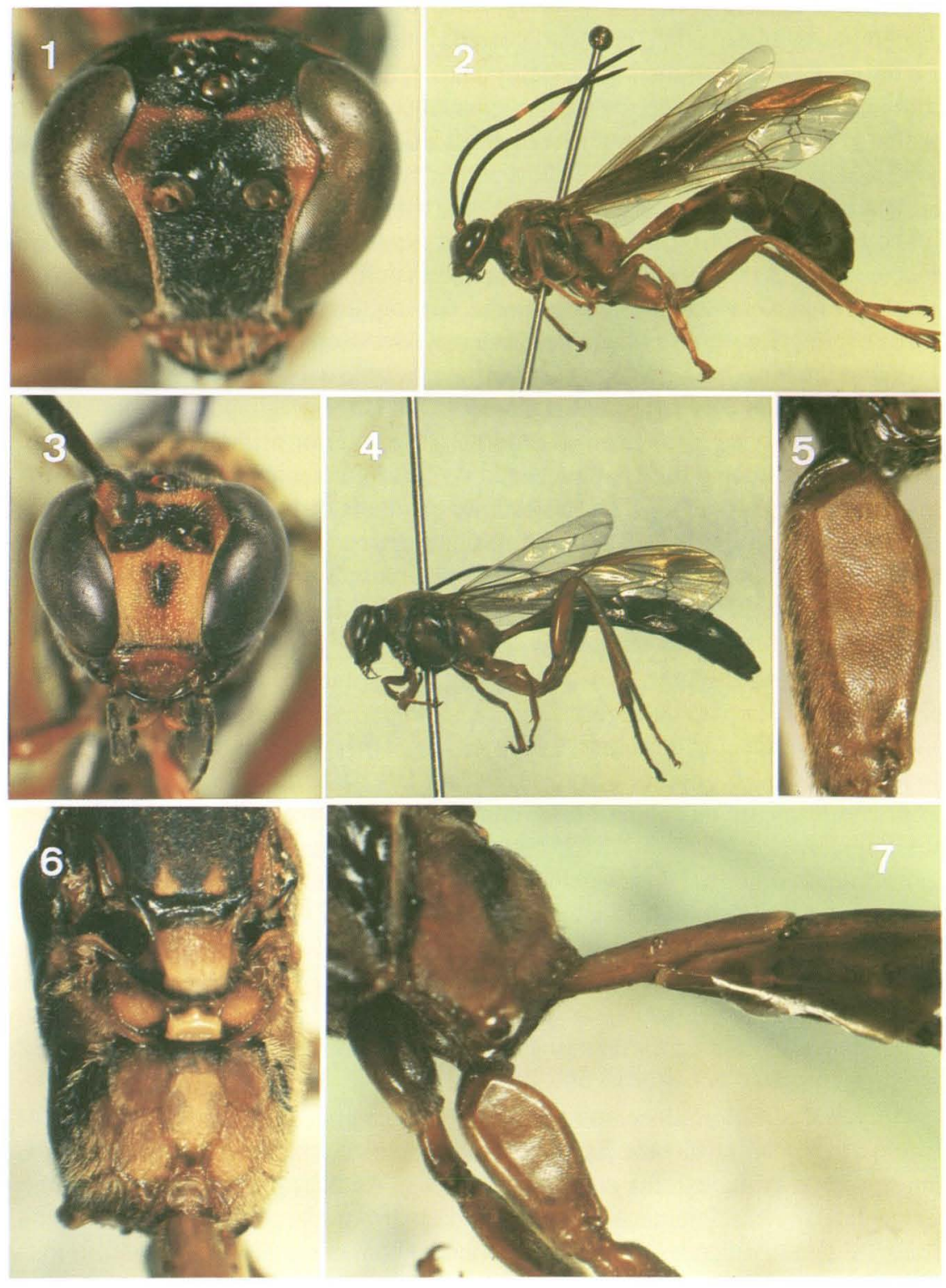

Figs 1-7. Labena fiorii sp.n. (1) cabeça da fêmea, em vista ântero-superior, (2) fêmea, em vista lateral (holótipo); (3) cabeça do macho, em vista anterior (alótipo); (4) macho, em vista lateral (alótipo); (5) face interna da coxa posterior da fêmea, com guia do ovipositor na base; (6) mesossoma da fêmea, em vista dorsal; (7) propódeo e parte anterior do metassoma da fêmea, em vista lateral. 
posterior e pequena carena epomial na parte látero-superior. Mesoscuto com pontuação muito densa e fina, com curta carena anteriormente entre os lobos mediano e laterais, estes pouco distintos. Mesopleura e metapleura densamente pontuadas, com pubescência curta, dourada e lisa, em parte com rugas finas no espéculo e parte posterior da mesopleura; escutelo com pilosidade bem desenvolvida e dourada. Asas posteriores com $\mathrm{Cul}$ completa. Tíbias anterior e média delgadas na parte proximal e dilatadas no meio, com cerdas grossas, curtas na superfície externa das tíbias média (13) e posterior (12). Carena submetapleural expandida na frente em lobo arredondado com rugas na superfície. Áreas propodeais definidas, área basal mais larga que longa, área peciolar unida a súpero-média, com algumas rugas longitudinais distais e área espiracular sem carena no lado externo. Metassoma com o primeiro esternito 0.6 vezes tão longo como a coxa posterior, alcançando o nível do espiráculo. Tergito do primeiro segmento com pontuação densa, os látero-tergitos 2 e 3 com carenas bem distintas, o segundo látero-tergito na parte anterior brilhante, sem cerdas, a superfície fracamente reticulada e bordo ventral fortemente sinuoso. Tergitos foscos, densamente pontuados. Coxa posterior com guia do ovipositor bem diferenciado, com bordo superior em arco, o inferior marginado por séries de cerdas muito curtas, a superfície interna da coxa plana com pontuação densa. Ovipositor 2,2 vezes o comprimento da tíbia posterior, com cerca de 20 dentes laterais muito finos no ápice, a superfície lateral fosca antes dos dentes, o bordo superior denteado.

Medidas: comprimento total 19,00; comprimento da asa anterior 16,83; comprimento e largura da cabeça 2,92 e 3,36; larguras interorbitais superior, média (entre as emarginações dos olhos) e inferior 1,40, 1,84 e 1,20; comprimento e largura do clípeo 0,60 e 1,08; comprimento da área malar 0,30; largura da base da mandíbula 0,60 , comprimento da antena 12,83 , com 43 flagelômeros e faixa amarelo-laranja nos flagelômeros XVIII a XXIII; comprimento e largura do escapo 0,80 e 0,50; comprimento e largura dos flagelômeros I, 0,76 e 0,26; II, 0,48 e 0,26; III, 0,40 e 0,26; IV, 0,40 e 0,26 ; V, 0,38 e 0,$28 ;$ VI, 0,36 e 0,28; VII, 0,34 e 0,28; VIII, 0,34 e 0,28 ; IX, 0,34 e 0,28; XXII, 0,26 e 0,28; XLII, 0,18 e 0,20 e XLIII, 0,56 e 0,14, com placa (sensila) terminal circular fracamente marginada. Comprimento da tíbia posterior 6,08; comprimento e largura do primeiro tergo 3,25 e 1,52; comprimento do pós-pecíolo 1,52; comprimento e largura distal do segundo tergito 2,40 e 2,52; comprimento do ovipositor 13,50.

Macho. Coloração como na fêmea; cabeça com a face e fronte amarelas, exceto a parte central da face, base do clípeo e escrobas antenais enegrecidas; a faixa amarelada na órbita externa contínua no vértice. Antenas pretas com escapo amarelado látero-ventralmente Asas tingidas de marrom-claro. Corpo mais delgado, tíbias I e II não dilatadas no meio, tíbia média com cerdas com distribuição mais linear do que na fêmea.

Medidas. Comprimento total 17,50; comprimento da asa anterior 12,50; comprimento e largura da cabeça 2,36 e 2,75; larguras interorbitais superior, média e inferior $1,20,1,46$ e 0,86 ; comprimento e largura do clípeo 0,44 e 0,86 ; comprimento da área malar 0,16; comprimento da antena 13,00, com 47 flagelômeros sem faixa transversal clara; comprimento e largura do escapo 0,64 e 0,36; comprimento e largura dos flagelômeros I, 0,60 e 0,24; II, 0,46 e 0,22; III, 0,36 e 0,22; IV, 0,36 
e 0,$22 ; \mathrm{V}, 0,36$ e 0,$22 ; \mathrm{VI}, 0,34$ e 0,$22 ;$ VII, 0,34 e 0,22 ; VIII, 0,34 e 0,$22 ;$ IX, 0,32 e 0,22 ; XXIII, 0,26 e 0,20; XLVI, 0,18 e 0,16 e XLVII, 0,28 e 0,12 (na base), com forma cônica e placa terminal muito pequena transversal. Comprimento da tíbia posterior 4,92; comprimento e largura do primeiro tergo 2,80 e 0,90; comprimento do pós-pecíolo 1,60; comprimento e largura do segundo tergo 2,00 e 1,40.

Holótipo fêmea e alótipo. BRAsiL, Paraná: Curitiba, 20/X/1978, F. Giacomel leg.. Parátipos. BrasiL, Santa Catarina: Seara (Nova Teutônia), uma fềmea, XI/1969, uma fêmea, X/1971, F. Plaumann leg. .

Material examinado. BRASIL, Paraná: Curitiba, uma fêmea, 16/VIII/1974, F. Giacomel leg.; Teixeira Soares, uma fêmea, III/1994, M. Ribeiro leg.. Santa Catarina: Seara (Nova Teutônia), um macho, XI/1969, uma fêmea, XI/1974, F. Plaumann leg.. Os tipos e espécimens examinados foram depositados na Coleção de Entomologia Pe. J.S. Moure, Departamento de Zoologia, Universidade Federal do Paraná.

Biologia. Hedypathes betulinus e Lebena fiorii foram coletados em galhos de erva-mate na Fazenda Floresta, da Empresa Leão Junior S.A., perto de Fernandes Pinheiro, município de Teixeira Soares, Paraná, nos meses de junho a novembro de 1997. Os galhos continham galerias com larvas e pupas do hospedeiro e do parasitóide. A emergência do parasitóide ocorre na parte subterminal anterior do casulo, perto da larva do hospedeiro, dentro da galeria; na fase de pupa e na emergência do parasitóide a larva hospedeira já está morta e enegrecida.

Discussão. Labena Cresson, 1864 é de distribuição ampla nas regiões Neotropical e Australiana com duas espécies Neárticas, as espécies da Austrália foram revisadas recentemente (GAULD \& HoLLOWAY 1986); na região Neotropical o catálogo de TOWNES \& TOWNES relaciona 12 espécies, das quais três do Brasil; GAULD \& HollowAY (1986) estimam cerca de 50 espécies para a região Neotropical. Labena fiorii é bem característica pelas estruturas e coloração, que diferem das descrições das espécies listadas por TownES \& TOWNES (1966).

Etimologia. o nome específico, fiorii, é dedicado ao professor Fioravante Giacomel, que coletou os ramos das aroeiras com os cerambicídeos Chydarteres striatus parasitados por este ichneumonídeo, em Curitiba, no bosque do "Parque da Cidade", na BR 116, e obteve os espécimens em laboratório.

AGRADECIMENTOS. Os autores agradecem ao Prof. Dr. Albino Morimasa Sakakibara as fotografias que ilustram este trabalho.

\section{REFERÊNCIAS BIBLIOGRÁFICAS}

Cresson, E.T. 1874. Descriptions of Mexican Ichneumonidae. Proc. Acad. Nat. Sci. Philadelphia: $374-414$

Cushman, R.A. 1922. New species of ichneumon-flies with taxonomic notes. Proc. U. S. Natl. Mus. 60 (21): 1-28.

Gauld, I.D. \& G.A. Holloway. 1986. Australian ichneumonids of the tribes

Labenini and Poecilocryptini. Bull. Br. Mus. nat. Hist. (Ent.) 53 (2): 107-149. Kriechbaumer, J. 1889. Nova genera et species Pimplidarum. Ent. Nachr. 15: 
307-312.

RoHwER, S.A. 1920. The North American Ichneumon-flies of the Tribes Labenini, Rhyssini, Xoridini, Odontomerini, and Phytodietini. Proc. U. S. Natl. Mus. 57: 405-413.

SzÉPLIGETI, V. 1914. Ichneumoniden aus der Sammlung des Ungarischen NationalMuseums. Ann. Mus. Natl. Hungarici 12: 414-434.

TownEs, H. \& M. TownES. 1966. A Catalogue and Reclassification of the Neotropic Ichneumonidae. Mem. Am. Entomol. Inst. 8: 1-367.

WAHL, D.B. 1996. Xenothyrini, a New Tribe of Labeninae, and a Key to the Tribes and Genera of Labeninae (Hymenoptera: Ichneumonidae). Proc. Entomol. Soc. Wash. 98 (1): 158-161.

Recebido em 29.VIII.1997; aceito em 11.XI.1998. 